\title{
A argumentação quase lógica em uma conversa entre os oradores Jesus Cristo e Nicodemos
}

\author{
The almost logical argumentation in a conversation between \\ the speakers Jesus Christ and Nicodemos
}

\author{
Max Silva da Rocha ${ }^{1}$ \\ Deywid Wagner de Melo ${ }^{2}$
}

\begin{abstract}
Resumo: Este trabalho tem como principal objetivo analisar o uso da argumentação quase lógica presente em um trecho da conversa entre os oradores Jesus Cristo e Nicodemos. Para tanto, toma a retórica como uma arte e/ou técnica de convencer e persuadir o outro pelo discurso. A partir desse entendimento, segue-se uma abordagem de linha qualitativa em que os dados são analisados de maneira processual, descritiva e interpretativista. O estudo embasa-se em autores como: Abreu (2009), Aristóteles (2011), Ferreira (2015), Meyer (2007), Perelman e Olbrechts-Tyteca ([1958] 2014), Rocha (2020), entre outros. A análise centra-se no discurso religioso bíblico, uma vez que o corpus é constituído a partir de um texto retirado do terceiro capítulo do livro bíblico evangelho de João. Por meio da conversa entre os oradores Jesus Cristo e Nicodemos, foi possível verificar como ambos agiram persuasivamente. Os resultados indicam que os referidos oradores recorreram aos argumentos quase lógicos (transitividade, ridículo, definição, regra de justiça, comparação, incompatibilidade e sacrifício) para tentar convencer e persuadir.
\end{abstract}

Palavras-chave: Argumentos quase lógicos. Discurso religioso. Persuasão.

\begin{abstract}
This work has as main objective to analyze the use of the quasi-logical argumentation present in an excerpt of the conversation between the speakers Jesus Christ and Nicodemus. For this, it takes rhetoric as an art and / or technique to convince and persuade the other through discourse. Based on this understanding, a qualitative approach is followed, in which data are analyzed in a procedural, descriptive and interpretative manner. The study is based on authors such as: Abreu (2009), Aristóteles (2011), Ferreira (2015), Meyer (2007), Perelman and Olbrechts-Tyteca ([1958] 2014), Rocha (2020), among others. The analysis focuses on the biblical religious discourse, since the corpus is constituted from a text taken from the third chapter of the biblical book gospel of John. Through the conversation between the speakers Jesus Christ and Nicodemus, it was possible to verify how both they acted persuasively. The results indicate that the aforementioned speakers resorted to quasi-logical arguments (transitivity, ridicule, definition, rule of justice, comparison, incompatibility and sacrifice) to try to convince and persuade.
\end{abstract}

Keywords: Quite logical arguments. Religious speech. Persuasion.

\footnotetext{
1 Universidade Federal de Alagoas, Programa de Pós-Graduação em Linguística e Literatura, Maceió; Universidade Estadual de Alagoas, Palmeira dos Índios, AL, Brasil. Endereço eletrônico: msrletras@gmail.com.

2 Universidade Federal de Alagoas, Faculdade de Letras, Arapiraca, AL, Brasil. Endereço eletrônico: linguagemeretorica@gmail.com.
} 


\section{Considerações iniciais}

O presente trabalho tem como principal objetivo analisar o uso da argumentação quase lógica presente na conversa entre os oradores Jesus Cristo e Nicodemos, procurando responder ao seguinte questionamento norteador: como os citadores oradores utilizam a argumentação quase lógica para tentar convencer e persuadir ${ }^{3}$ ? A busca por essa resposta fundamenta o interesse principal desta investigação.

O texto analisado é pertencente ao livro bíblico intitulado evangelho de João ${ }^{4}$ e localizase no capítulo 3, versículos de 1 ao 12. Esse texto é muito importante para a cristandade, pois mostra a necessidade de os adeptos da religião cristã passarem pela cerimônia do batismo para só assim poderem ser considerados cristãos. Mesmo existindo diversidades entre os cristãos acerca do batismo, o texto bíblico apresenta a necessidade desse ato simbólico. O texto em tela é encontrado na Bíblia ${ }^{5}$ Sagrada, principal livro da religiosidade cristã. A Bíblia utilizada foi Almeida (1999) revista e atualizada, pelo fato de João Ferreira de Almeida ter sido um respeitável tradutor da Bíblia para a Língua Portuguesa, razão por que se justifica essa escolha.

Outros trabalhos já foram realizados sobre textos bíblicos ou com temáticas religiosas cristãs. Silva (2013), por exemplo, estudou as técnicas argumentativas do orador Jesus Cristo, quando este pregava o sermão do monte. $\mathrm{O}$ referido autor mostrou de forma pormenorizada como o orador Jesus Cristo utilizou-se de mecanismos argumentativos para pregar o sermão do monte e tentar persuadir o auditório ali presente.

No entanto, a diferença principal deste trabalho para o de Silva (2013) reside no fato de estudar apenas os argumentos quase lógicos ${ }^{6}$ durante a conversa entre o orador Jesus Cristo e o orador Nicodemos. Diante disso, há outra perspectiva, o que mostra uma novidade e/ou justificativa para a realização deste estudo, uma vez que, possivelmente, o texto selecionado ainda não foi analisado sob o olhar e os procedimentos utilizados nesta abordagem.

Em um trabalho recente, Rocha e Santos (2018) mostraram como oradores religiosos cristãos do agreste alagoano utilizaram-se de recursos persuasivos para ganhar a confiança e tentar persuadir o auditório. Os autores, partindo dos estudos retóricos da linguagem, realizaram

\footnotetext{
${ }^{3}$ Neste trabalho, convencer e persuadir são considerados distintamente. "Para quem está preocupado com o caráter racional da adesão, convencer é mais do que persuadir" (PERELMAN; OLBRECHTS-TYTECA, 2014 [1958], p. 30).

${ }^{4} \mathrm{O}$ livro de João é um dos quatro evangelhos canônicos e o quarto livro do novo testamento contido na Bíblia Sagrada, principal livro do Cristianismo. A temática presente no livro de João mostra um relato da vida, do ministério, da morte e da ressurreição de Jesus de Nazaré.

${ }^{5}$ Bezerra (2019, p. 20) afirma que a "Bíblia é antes de tudo um texto, ou melhor, um conjunto deles, escritos em diferentes gêneros [...], em diferentes lugares e épocas, por diferentes autores".

${ }^{6}$ Para uma melhor compreensão do uso da argumentação quase lógica, sugere-se consultar os trabalhos de Rocha e Santos (2020) e Rocha (2020).
} 
uma análise consistente que evidenciou as artimanhas persuasivas do gênero discursivo sermão oral, proferido por oradores cristãos (protestantes) de Alagoas. Isso contribui com este estudo na medida em que os referidos autores mostraram como proceder ao se realizar uma análise retórica de um gênero ou texto da esfera religiosa cristã.

Assim, a partir dessas e de outras contribuições importantes no campo dos estudos retóricos da linguagem, pretende-se, neste estudo, analisar o uso da argumentação quase lógica presente em um trecho da conversa entre os oradores Jesus Cristo e Nicodemos. Diante disso, busca-se propiciar uma contribuição para o estudo retórico do discurso religioso cristão que, possivelmente, está prenhe de elementos de natureza persuasiva. Nesse sentido, verificar como os citados oradores recorrem aos argumentos quase lógicos para tentar persuadir, é mostrar a importância das técnicas persuasivas presentes no discurso religioso ${ }^{7}$, neste caso, no cristão.

Esta investigação está dividida em alguns tópicos: o primeiro discorre sobre os estudos retóricos da linguagem; o segundo trata da argumentação quase lógica; o terceiro apresenta os argumentos quase lógicos; o quarto mostra os procedimentos metodológicos, as análises e as considerações finais. Assim, todos esses pontos descritos foram organizados sistematicamente para mostrar como os oradores Jesus Cristo e Nicodemos agem persuasivamente, utilizando-se de recursos/dispositivos argumentativos provindos da arte de persuadir pelo discurso.

\section{Os estudos retóricos da linguagem}

Este trabalho situa-se nos estudos retóricos da linguagem, nas perspectivas antiga e nova da Retórica. No que concerne a uma perspectiva mais antiga, é necessário frisar as pontuações teóricas dadas por Aristóteles (2011), pois foi com o referido filósofo grego que os estudos retóricos foram sistematizados e organizados de forma consistente.

Aristóteles (2011) foi quem primeiro organizou os cânones da chamada Antiga Retórica. Segundo ele, a Retórica deve ser entendida como uma "faculdade de observar, em cada caso, o que este encerra de propósito para criar a persuasão. Nenhuma outra arte possui tal função" (ARISTÓTELES, 2011, p. 44). Assim sendo, a Retórica fornece meios para que o analista (retórico) identifique e analise o que há de elemento persuasivo nos mais diversos discursos. É nesse meio que a persuasão é evocada pelo orador, ou seja, criada a partir do uso de elementos retóricos e/ou persuasivos.

No estudo em apreço, procura-se mostrar como oradores recorrem aos argumentos quase lógicos para criar tentativas de convencimento e de persuasão. Desse modo, infere-se que

\footnotetext{
${ }^{7}$ De acordo com Ferreira (2015, p. 89), “o discurso religioso é repleto de argumentação”. O discurso religioso mencionado é o bíblico de linha cristã.
} 
a persuasão é criada pelo orador, uma vez que ela não existe $a$ priori, mas é evocada e posta no discurso de maneira estratégica, a partir de dispositivos argumentativos definidos, como defende Morais (2019). De acordo com Aristóteles (2011, p. 45), “a persuasão é obtida graças ao caráter pessoal do orador, quando o discurso é proferido de tal maneira que nos faz pensar que o orador é digno de crédito".

O orador é o principal responsável por criar a persuasão e isso acontece por meio do discurso retórico. Nesse sentido, para entender como o discurso está prenhe de elementos persuasivos, o analista retórico lança mão da Retórica, pois esta tem "o poder, diante de quase qualquer questão que nos é apresentada, de observar e descobrir o que é adequado para persuadir. E esta é a razão por que a retórica não aplica suas regras a nenhum gênero particular e definido" (ARISTÓTELES, 2011, p. 44-45).

Após toda a sistematização e definição de Retórica dada por Aristóteles (2011), surgiram outras contribuições, a exemplo da Nova Retórica de Perelman e Olbrechts-Tyteca ([1958] 2014). Estes autores, partindo, naturalmente, da obra do filósofo grego, contribuíram na medida em que, na segunda metade do século XX, mais precisamente em 1958, lançaram a obra intitulada Tratado da argumentação: a nova retórica. O principal tributo dessa obra foi a classificação dos quatro grandes grupos de argumento.

Além do agrupamento, Perelman e Olbrechts-Tyteca ([1958] 2014, p. 220) cunharam uma nova definição para a Retórica. Nas palavras dos autores, a Retórica "é o estudo das técnicas discursivas que permitem provocar ou aumentar a adesão dos espíritos às teses que se lhes apresentam ao assentimento". Por meio da Retórica, é possível sim estudar e desvelar, no discurso, as técnicas argumentativas que são utilizadas com fins persuasivos.

Retomando aos grandes grupos de argumentos teorizados na obra de Perelman e Olbrechts-Tyteca ([1958] 2014), é importante ratificar que são quatro tipologias distintas, a saber: os argumentos quase lógicos, os argumentos baseados na estrutura do real, os argumentos que fundam a estrutura do real e os argumentos que dissociam noções. Cada uma dessas tipologias possui ramificações, ou seja, outros argumentos imbricados.

Como o objetivo deste trabalho é analisar apenas os argumentos quase lógicos presentes na conversa entre os oradores Jesus Cristo e Nicodemos, apenas essa tipologia será definida e caracterizada de forma pormenorizada. Não que as outras tipologias deixem de ser importantes para os estudos retóricos da linguagem, mas a escolha se dá única e exclusivamente pelo recorte teórico previamente estabelecido para este estudo. 


\section{A argumentação quase lógica no texto bíblico}

Cada um dos argumentos quase lógicos é aparentado com um princípio lógico, como a definição, a transitividade, entre outros; e, assim como eles, não fazem apelo à experiência (REBOUL, 2004). Eles se ancoram numa aparência de logicidade, embora não sejam puramente lógicos e podem sim ser refutados. A argumentação quase lógica se apresentará "de uma forma mais ou menos explícita. Ora o orador designará os raciocínios formais aos quais se refere, prevalecendo-se do pensamento lógico, ora estes constituirão apenas uma trama subjacente" (PERELMAN; OLBRECHTS-TYTECA, [1958] 2014, p. 220).

Abreu (2009) afirma que os argumentos quase lógicos, assim como os outros três tipos de argumento (baseados na estrutura do real, ligações que fundam a estrutura do real e os que dissociam noções), são utilizados por oradores como técnicas argumentativas para ganhar a adesão do auditório. Desse modo, para o referido autor, as técnicas argumentativas são conceituadas como os fundamentos "que estabelecem a ligação entre as teses de adesão inicial e a tese principal. Essas técnicas compreendem dois grupos principais: os argumentos quase lógicos e os argumentos fundamentados na estrutura do real” (ABREU, 2009, p. 47).

As técnicas argumentativas utilizadas pelos oradores Jesus Cristo e Nicodemos estão fundamentadas em elementos retóricos. Possivelmente, verificar-se-á que ambos os oradores utilizam estratégias persuasivas e tentam, a todo instante, convencer e persuadir. Em toda argumentação de natureza retórica, há três elementos essenciais para que se estabeleça a persuasão, quais sejam: o orador, o auditório e o discurso. Esses três meios de persuadir são correspondentes a ethos, pathos e logos.

O ethos refere-se ao caráter do orador e caracteriza-se como a imagem de si projetada, criada no momento da argumentação. Desse modo, diz-se que o ethos "é uma excelência que não tem objeto próprio, mas se liga à pessoa, à imagem que o orador passa de si mesmo, e que o torna exemplar aos olhos do auditório, que então se dispõe a ouvi-lo e a segui-lo" (MEYER, 2007, p. 34-35).

O pathos é entendido como um conjunto de sentimentos, paixões que o orador desperta no auditório social. Desse modo, o pathos "é o conjunto de valores implícitos das respostas fora de questão, que alimentam as indagações que um indivíduo considera como pertinentes" (MEYER, 2007, p. 39).

O logos é caracterizado como a argumentação, isto é, o discurso persuasivo dotado de artimanhas retóricas utilizadas de forma estratégica pelo orador. Assim sendo, o logos "deve poder expressar as perguntas e as respostas preservando sua diferença” (MEYER, 2007, p. 40). 
No estudo em tela, o ethos é caracterizado pelas imagens criadas/projetadas pelos oradores Jesus Cristo e Nicodemos; o pathos caracteriza-se pelos sentimentos, pelas paixões despertadas; o logos acontece por meio do encadeamento dos argumentos quase lógicos no próprio discurso. Diante disso, a tríade aristotélica (ethos, pathos e logos) está imbricada, indissociável no processo argumentativo em estudo, pois são provas retóricas que organizam e efetivam o acontecimento da argumentação.

Durante a conversa entre os oradores Jesus Cristo e Nicodemos, será possível perceber que o auditório é constituído pelos próprios oradores quando trocam de papéis comunicativos. Ou seja, quando o orador Jesus Cristo está com o turno ${ }^{8}$ de fala, Nicodemos se constitui como um ouvinte, integrante do auditório; quando Nicodemos está com o turno de fala, Jesus Cristo passa a ser o ouvinte e a integrar o auditório. No momento do diálogo, só estavam presentes os dois oradores, por isso a troca de papéis comunicativos caracterizando o auditório.

Acerca do auditório, Abreu (2009, p. 39) assegura que se refere ao "conjunto de pessoas que queremos convencer e persuadir". Na conversa entre os oradores Jesus Cristo e Nicodemos, verifica-se que Jesus Cristo tenta convencer e persuadir Nicodemos acerca de alguns pontos religiosos. Em contrapartida, Nicodemos tenta contra-argumentar e também persuadir a Jesus Cristo. Conforme Abreu (2009, p. 39), o auditório pode ser composto por “um pequeno grupo, dentro de uma empresa, mas pode ser apenas uma única pessoa: um amigo, um cliente" (ABREU, 2009, p. 39, grifo do pesquisador). No texto bíblico, parece que os oradores Jesus Cristo e Nicodemos tinham alguma afinidade/amizade, pois marcaram de se encontrar à noite para conversar sobre alguns assuntos de natureza religiosa.

Abreu (2009) classifica o auditório em universal e particular. Nas palavras do referido autor, o auditório universal "é um conjunto de pessoas sobre as quais não temos controle de variáveis"; e o auditório particular "é um conjunto de pessoas cujas variáveis controlamos" (ABREU, 2009, p. 40).

Assim sendo, observa-se que durante a conversa entre os oradores Jesus Cristo e Nicodemos, existe a presença dos dois tipos de auditório, se forem considerados os seguintes pontos centrais: durante a conversação entre apenas os dois oradores e quando eles trocam de papéis comunicativos, o auditório é particular, pois ambos os oradores se conhecem e as variáveis são controladas; mas se forem consideras as pessoas que Nicodemos poderia influenciar posteriormente, percebe-se que o auditório será universal, pois não há um controle das variáveis e este tipo de auditório (universal) consiste em uma criação mental do orador

\footnotetext{
${ }^{8}$ O turno conversacional diz respeito "à produção de um falante enquanto ele está com a palavra" (FÁVERO, ANDRADE, AQUINO, 1999, p. 35).
} 
relacionada a uma racionalidade intersubjetiva. Nicodemos era um intelectual na época e tinha um grande prestígio social entre as autoridades. Se ele fosse persuadido poderia levar outras pessoas a crer no mesmo ensinamento religioso cristão (batismo).

\section{As especificidades dos argumentos quase lógicos}

Como fora dito anteriormente, este trabalho se vale apenas dos argumentos quase lógicos e não se debruça sobre os baseados na estrutura do real e nos demais tipos por estes não serem o foco de investigação. Nesse sentido, é preciso discorrer sobre as ramificações dos argumentos quase lógicos e outras possíveis conceituações imprescindíveis para o entendimento da referida tipologia.

Ainda em se tratando da conceituação dos argumentos quase lógicos, considera-se que eles se apresentam de maneira explícita no discurso e têm sua força "persuasiva na proximidade (semelhança) com argumentos formais: o orador designará os raciocínios formais aos quais se refere prevalecendo-se do prestígio do pensamento lógico, ora estes constituirão uma trama subjacente" (FERREIRA, 2015, p. 149-150).

Desse modo, por meio da aparência de logicidade presente nos argumentos, é possível proceder às tentativas de persuasão. Os argumentos quase lógicos estão subdivididos em dez tipos específicos, conforme a Nova Retórica. São eles: incompatibilidade, ridículo, definição, regra de justiça, reciprocidade, transitividade, inclusão das partes no todo, divisão do todo em suas partes, comparação e sacrifício. Todos esses dez argumentos foram teorizados e agrupados por Perelman e Olbrechts-Tyteca ([1958] 2014). Por questões teóricas, discorre-se apenas de sete dos dez argumentos quase lógicos, pois foram os mais utilizados no corpus.

$\mathrm{O}$ argumento de incompatibilidade mostra as possíveis contradições presentes no discurso retórico. Em vista disso, "a incompatibilidade é sempre relativa a circunstâncias contingentes, sejam estas constituídas por leis naturais, fatos particulares ou decisões humanas" (PERELMAN; OLBRECHTS-TYTECA, [1958] 2014, p. 223).

O argumento do ridículo acontece quando uma situação discursiva é posta de maneira conflituosa e gera tensões. Nesse sentido, “o ridículo é aquilo que merece ser sancionado pelo riso [...] uma afirmação é ridícula quando entra em conflito, sem justificação, com uma opinião aceita” (PERELMAN; OLBRECHTS-TYTECA, [1958] 2014, p. 233).

O argumento de definição ocorre quando o orador lança mão de conceituações, classificações de objetos e/ou referentes do mundo compartilhado. Diante disso, compreendese que "o procedimento mais característico de identificação completa consiste no uso das definições" (PERELMAN; OLBRECHTS-TYTECA, [1958] 2014, p. 238). 
$\mathrm{O}$ argumento da regra de justiça é aquele que oferece um tratamento igualitário a aspectos de uma mesma situação discursiva. Desse modo, duas situações semelhantes precisam receber os mesmos valores. Por isso, "a regra de justiça requer a aplicação de um tratamento idêntico a seres ou a situações que são integrados numa mesma categoria” (PERELMAN; OLBRECHTS-TYTECA, [1958] 2014, p. 248).

$\mathrm{O}$ argumento de transitividade aponta para as relações transitivas em determinadas situações. Desse modo, por meio do referido argumento, é possível verificar "que existe a mesma relação entre os termos a e b e entre os termos b e c, à conclusão de que ela existe entre os termos a e c: as relações de igualdade, de superioridade, de inclusão, de ascendência são relações transitivas" (PERELMAN; OLBRECHTS-TYTECA, [1958] 2014, p. 257).

$\mathrm{O}$ argumento de comparação acontece na maioria dos discursos, visto que "a argumentação não poderia ir muito longe sem recorrer a comparações, nas quais se cotejam vários objetos para avaliá-los um em relação ao outro" (PERELMAN; OLBRECHTSTYTECA, [1958] 2014, p. 274).

O argumento de sacrifício também trata de um argumento de comparação, já que atesta o sacrifício a ser realizado para se conseguir algum objetivo específico. Assim sendo, "na argumentação pelo sacrifício, este deve medir o valor atribuído àquilo por que se faz o sacrifício" (PERELMAN; OLBRECHTS-TYTECA, [1958] 2014, p. 282), pois, às vezes, é preciso abdicar de algumas coisas para conquistar outras.

Esses sete (e os outros) argumentos quase lógicos estão a serviço de oradores para tentar convencer e persuadir. Assim, o uso estratégico pode resultar numa possível adesão do auditório social. Nesse sentido, presume-se que na conversação entre os oradores Jesus Cristo e Nicodemos a utilização desses (e outros) argumentos não acontece de maneira inconsciente. Há, portanto, um objetivo argumentativo: o de querer levar o outro ao assentimento daquilo que é apresentado como digno de crédito, confiança.

\section{Os passos metodológicos e a análise retórica}

Este trabalhou utilizou-se dos postulados da abordagem qualitativa para escolher, selecionar, interpretar e analisar as informações adquiridas durante todo o processo de investigação empírica (FLICK, 2009). Nesse sentido, tem-se o entendimento de que "a pesquisa qualitativa evita números, lida com interpretações das realidades sociais" (BAUER; GASKELL; ALLUM, 2002, p. 23). Assim, numa perspectiva processual, o que se fez neste trabalho foi analisar como os oradores Jesus Cristo e Nicodemos utilizaram os argumentos quase lógicos para tentar convencer e persuadir. 
No que concerne à análise retórica propriamente dita, o ponto de partida precisa ser o contexto em que o texto acontece. Conforme pontua Leach (2002, p. 296), "o contexto do discurso deve ser o primeiro ponto a ser levado em consideração ao se embarcar em uma análise retórica, seja ao escolher um discurso oral, uma imagem ou um documento escrito". Desse modo, a análise retórica está voltada às artimanhas da persuasão, isto é, aos elementos que são utilizados por oradores para persuadir. A conversa entre os oradores Jesus Cristo e Nicodemos pertence a esse espaço marcadamente persuasivo.

Em se tratando do contexto em que se encontravam os dois oradores, destaca-se que Jesus Cristo estava em Jerusalém durante a festa da páscoa e lá fez sinais sobrenaturais. Nicodemos também estava em Jerusalém e foi uma das várias pessoas que ficaram maravilhadas com os feitos de Jesus Cristo. O relato histórico da Bíblia mostra que Nicodemos era um mestre em Israel, um intérprete e doutor da lei judaica. Além disso, ele ocupava uma posição proeminente no sinédrio, uma espécie de corte suprema dos judeus da época.

Ao anoitecer, Nicodemos foi ao encontro de Jesus. Possivelmente, Nicodemos preferiu se encontrar com Jesus à noite pelo fato de os judeus não concordarem com tal encontro. Outra possibilidade é que Jesus trabalhava (ensinava a doutrina cristã) muito durante o dia e Nicodemos evitou incomodá-lo. No início da conversa, observa-se que Nicodemos não faz nenhuma pergunta a Jesus, mas parece claro que o objetivo da visita foi a dúvida de como alcançar o céu. Quando Jesus respondeu, Nicodemos, mesmo sendo um doutor da lei, não conseguiu entender a linguagem conotativa utilizada por Jesus Cristo. É o que se pode ver no fragmento selecionado:

Havia, entre os fariseus, um homem chamado Nicodemos, um dos principais dos judeus. 2 Este, de noite, foi ter com Jesus e lhe disse: Rabi, sabemos que és mestre vindo da parte de Deus; porque ninguém pode fazer estes sinais que tu fazes, se Deus não estiver com ele. 3 A isto, respondeu Jesus: Em verdade, em verdade te digo que, se alguém não nascer de novo, não pode ver o reino de Deus. 4 Perguntou-lhe Nicodemos: Como pode um homem nascer, sendo velho? Pode, por ventura, voltar ao ventre materno e nascer segunda vez? 5 Respondeu Jesus: Em verdade, em verdade te digo: quem não nascer da água e do Espírito não pode entrar no reino de Deus. 6 O que é nascido da carne é carne; o que é nascido do Espírito é espírito. 7 Não te admires de eu te dizer: importa-vos nascer de novo. $8 \mathrm{O}$ vento sopra onde quer, ouves a sua voz, mas não sabes donde vem, nem para onde vai; assim é o todo o que é nascido do Espírito. 9 Então, lhe perguntou Nicodemos: Como pode suceder isto? Acudiu Jesus: $10 \mathrm{Tu}$ és mestre em Israel e não compreendes estas coisas? $11 \mathrm{Em}$ verdade, em verdade te digo que nós dizemos o que sabemos e testificamos o que temos visto; contudo, não aceitais o nosso testemunho. $12 \mathrm{Se}$, tratando de coisas terrenas, não me credes, como crereis se vos falar das celestiais? (Fonte: João $3: 1-12)$. 
No fragmento destacado, o narrador é o próprio escritor do Livro, ou seja, o apóstolo João. Ele começa descrevendo que Nicodemos era um fariseu, isto é, um membro de um grupo religioso judaico, que vivia na estrita observância das escrituras religiosas e da tradição oral. Só que Nicodemos não era qualquer fariseu, mas sim, "um dos principais dos judeus". À noite, de forma secreta, por questões conflituosas entre os judeus e os primeiros cristãos, Nicodemos encontrou-se com Jesus Cristo.

Em sua primeira intervenção, o orador Nicodemos diz: "Rabi, sabemos que és mestre vindo da parte de Deus; porque ninguém pode fazer estes sinais que tu fazes, se Deus não estiver com ele". Neste primeiro trecho, verifica-se a presença do argumento de transitividade, pois os possíveis "sinais" realizados pelo orador Jesus Cristo também são realizados por Deus e viceversa. Assim, a partir da fala de Nicodemos, infere-se que Jesus Cristo só faz os "sinais" porque Deus também faz. Logo, por meio dessa transição, Jesus é Deus e isso é confirmado por meio do argumento quase lógico da transitividade.

Como resposta, o orador Jesus Cristo argumenta: "Em verdade, em verdade te digo que, se alguém não nascer de novo, não pode ver o reino de Deus. 4 Perguntou-lhe Nicodemos: Como pode um homem nascer, sendo velho? Pode, por ventura, voltar ao ventre materno e nascer segunda vez?". Nesta amostragem, observa-se o uso do argumento do ridículo, uma vez que a afirmação do orador Jesus Cristo entrou em conflito com aquilo que Nicodemos acreditava. Assim, a opinião aceita é a de que não se pode nascer de novo, mas não era sobre isso que Jesus estava se referindo, por isso a presença do argumento quase lógico do ridículo.

Em seguida, o orador Jesus Cristo afirma: "Em verdade, em verdade te digo: quem não nascer da água e do Espírito não pode entrar no reino de Deus". Na argumentação em tela, infere-se, implicitamente, que o orador Jesus Cristo se utilizou do argumento da definição, pois está se referindo, repita-se, de forma implícita, ao batismo cristão bíblico que, simbolicamente, é entendido na linha cristã como um "novo nascimento". Mesmo existindo as diferenças entre as ramificações cristãs, entende-se que esse "nascimento" faz referência à água porque há o processo de imersão; e do espírito porque se trata da crença cristã na presença do Espírito Santo de Deus. Mais uma vez, verifica-se o uso estratégico do argumento quase lógico no discurso do orador Jesus Cristo.

Ao continuar argumentando, o orador Jesus Cristo assevera: "O que é nascido da carne é carne; o que é nascido do Espírito é espírito. 7 Não te admires de eu te dizer: importa-vos nascer de novo". Nota-se, nesta passagem, que o orador recorreu ao argumento intitulado regra de justiça, pois propiciou um tratamento igualitário para duas situações, ao dizer que o que é nascido da carne é carne; e o que é nascido do espírito é espírito. Há, desse modo, duas 
categorias (carne e espírito) que são postas de maneira paralela pelo orador Jesus Cristo a fim de tentar persuadir. Ainda com o turno de fala, o orador Jesus Cristo afirma: "O vento sopra onde quer, ouves a sua voz, mas não sabes donde vem, nem para onde vai; assim é o todo o que é nascido do Espírito”. Ao encadear essa argumentação, o orador Jesus Cristo lança mão do argumento da comparação, pois avalia e coteja duas situações: o vento e aquele que é nascido do espírito. Logo, percebe-se a comparação entre esses dois referentes. O argumento é posto de maneira persuasiva para tentar conquistar a adesão do auditório (Nicodemos).

Após a comparação feita por Jesus, o orador Nicodemos adquire o turno de fala e questiona: “Como pode suceder isto?". Prontamente, o orador Jesus Cristo recupera o turno de fala e responde: “Tu és mestre em Israel e não compreendes estas coisas?”. O orador Jesus Cristo, para responder ao questionamento feito pelo orador Nicodemos, recorre, de forma persuasiva, ao argumento de incompatibilidade. Essa ideia é transmitida porque se Nicodemos se intitula mestre em Israel e em aspectos de natureza religiosa (por ele ser fariseu e doutor da lei), esperava-se que ele entendesse o que Jesus tinha dito. Como não o fez, o orador Jesus Cristo, de forma estratégica, mostrou a contradição no discurso de Nicodemos.

O orador Jesus Cristo continua com o turno de fala e diz: "Em verdade, em verdade te digo que nós dizemos o que sabemos e testificamos o que temos visto; contudo, não aceitais o nosso testemunho". Verifica-se, neste momento, que o orador se utiliza do argumento do sacrifício. Assim, mesmo dizendo, testificando, pregando, mostrando por meio de testemunhos, ainda assim há uma negação às ações realizadas. Há um sacrifício, qual seja, as tentativas para mostrar as possíveis benesses para Nicodemos e todos aqueles que aceitassem e acreditassem no "testemunho".

No último momento do fragmento destacado, o orador Jesus Cristo destaca: “Se, tratando de coisas terrenas, não me credes, como crereis se vos falar das celestiais?". Mais uma vez, o orador evoca o argumento da incompatibilidade para tentar persuadir Nicodemos. Assim, conforme o discurso do orador Jesus Cristo, é impossível acreditar nas coisas "celestiais" se também não crer, primeiramente, nas coisas mais simples, "terrenas". Por isso, visualiza-se que a tentativa de persuadir acontece nesse uso estratégico entre as duas realidades (terrena e celestial).

Após as análises dos argumentos quase lógicos encontrados no texto bíblico, é possível compreender que a conversa entre os oradores Jesus Cristo e Nicodemos está prenhe de técnicas argumentativas. Foram os argumentos de natureza quase lógica que propiciaram as artimanhas argumentativas utilizadas por ambos os oradores. Como é possível observar, o orador Jesus Cristo fez mais uso do turno de fala do que o orador Nicodemos, o que caracterizou, no discurso, 
uma relação de assimetria ${ }^{9}$. Para uma visualização mais didática dos argumentos utilizados pelos oradores, eis a seguir o quadro com o agrupamento dos argumentos:

Quadro 1

\begin{tabular}{|c|c|}
\hline \multirow{4}{*}{ ARGUMENTAÇÃO QUASE LÓGICA } & ARGUMENTOS ENCONTRADOS \\
\cline { 2 - 3 } & NO CORPUS \\
\cline { 2 - 2 } & Transitividade \\
Ridículo & Definição \\
& Regra de justiça \\
Comparação \\
& Incompatibilidade (2) \\
& Sacrifício \\
\hline
\end{tabular}

Fonte: elaborado pelos autores.

O quadro mostra que os oradores Jesus Cristo e Nicodemos fizeram uso dos seguintes argumentos quase lógicos: transitividade, ridículo, definição, regra de justiça, comparação, incompatibilidade (duas vezes) e sacrifício. Isso atesta que a ação retórica durante a conversa entre ambos os oradores se fundamenta nos argumentos em tela. Assim, dos dez argumentos quase lógicos presentes em Perelman e Olbrechts-Tyteca ([1958] 2014), sete deles apareceram no trecho analisado da conversa entre os referidos oradores. Isso autoriza dizer que o texto bíblico porta argumentos de natureza quase lógica e que os oradores Jesus Cristo e Nicodemos agiram retoricamente durante a conversação estudada.

\section{Considerações finais}

Este estudo se propôs a analisar o uso da argumentação quase lógica num trecho da conversa entre os oradores Jesus Cristo e Nicodemos. Por meio da análise realizada, verificouse que ambos os oradores recorreram aos argumentos quase lógicos para argumentar. Tanto Jesus Cristo quanto Nicodemos fizeram uso de técnicas argumentativas com vistas a persuadir.

No que concerne à tipologia dos argumentos quase lógicos utilizados pelos oradores, notou-se que o uso dos argumentos não é neutro e fornece informações de como os oradores Jesus Cristo e Nicodemos conseguiram agir persuasivamente.

A partir das estratégias argumentativas utilizadas pelos oradores, depreende-se que Jesus Cristo foi quem conseguiu convencer e persuadir Nicodemos. Quem atesta isso são outros textos encontrados no próprio livro do evangelho de João. Por exemplo, em João 7:52 é dito:

\footnotetext{
${ }^{9}$ A assimetria diz respeito a uma hierarquia linguisticamente marcada entre os interactantes de uma situação discursiva, em que um dos participantes do evento de fala detém o poder da palavra e comanda o turno conversacional (MELO JUNIOR, 2016, p. 15).
} 
"Nicodemos, um deles, que antes fora ter com Jesus, 'perguntou-lhes: Acaso, a nossa lei julga um homem, sem primeiro ouvi-lo e saber o que ele fez?". Neste trecho, percebe-se que Nicodemos, mesmo também sendo um fariseu, defende Jesus Cristo diante dos outros fariseus que queriam prender o líder do Cristianismo.

Mais à frente, em João 19:39, ao abordar o sepultamento de Jesus, é dito: “e também Nicodemos, aquele que anteriormente viera ter com Jesus à noite, foi, levando cerca de cem libras de um composto de mirra e aloés". Nesta amostragem, verifica-se que Nicodemos contribui financeiramente para o cuidado do corpo de Jesus Cristo após a crucificação. Isso aponta para uma possibilidade de Nicodemos ter sido persuadido a seguir os ensinamentos dados por Jesus Cristo, pois os relatos bíblicos mostram uma relação muito próxima entre Jesus e Nicodemos após o encontro nas caladas da noite.

Retomando ao questionamento norteador: como os oradores Jesus Cristo e Nicodemos utilizam a argumentação quase lógica para tentar convencer e persuadir? Foi possível perceber que os oradores Jesus Cristo e Nicodemos utilizaram a argumentação quase lógica de forma estratégica, por meio dos argumentos persuasivos, tentaram convencer e persuadir. Assim, o possível êxito da argumentação está imbricado nos elementos de natureza retórica utilizados por ambos os oradores.

Portanto, acredita-se que este trabalho contribui, de algum modo, com os estudos retóricos da linguagem e, mais ainda, com o estudo retórico do discurso religioso bíblico. Nesse discurso específico, verificou-se o uso acentuado da argumentação quase lógica, o que autoriza a dizer que a conversa entre os oradores Jesus Cristo e Nicodemos é organizada e efetivada a partir dos argumentos encontrados. Por isso, afirma-se que, no texto analisado, o objetivo principal é levar o outro ao assentimento das ideias apresentadas no discurso.

\section{Referências}

A BÍBLIA SAGRADA. Trad. João Ferreira de Almeida. 2. ed. Barueri/SP: Sociedade Bíblica do Brasil, 1999. 896p. Velho Testamento e Novo Testamento.

ABREU, A. S. A arte de argumentar: gerenciando razão e emoção. São Paulo: Ateliê, 2009.

ARISTÓTELES. Retórica. Trad. Edson Bini. São Paulo: Edipro, 2011.

BAUER, M. W.; GASKELL, G.; ALLUM, N. C. Qualidade, quantidade e interesses do conhecimento: evitando confusões. In: BAUER, M. W.; GASKELL, G. Pesquisa qualitativa com texto, imagem e som: um manual prático. 13. ed. Petrópolis: Vozes, 2002.

BEZERRA, B. G. A palavra de Deus na palavra humana: gênero, preconceito e tradução da bíblia à luz da linguística. São Paulo: Pá de Palavra, 2019. 
DA ROCHA, M. S.; OLIVEIRA SANTOS, M. F. Os argumentos quase lógicos e os lugares da argumentação no gênero propaganda oral radiofônica. Domínios de Lingu@gem, v. 14, n. 1, p. 196-217, 11 fev. 2020.

FÁVERO, L. L.; ANDRADE, M. L. C. V. O.; AQUINO, Z. G. O. Oralidade e escrita: perspectivas para o ensino de língua materna. São Paulo: Cortez, 1999.

FERREIRA, L. A. Leitura e Persuasão: princípios de análise Retórica. São Paulo: Contexto, 2015.

FLICK, U. Introdução à pesquisa qualitativa. 3. ed. Porto Alegre: Artmed, 2009.

LEACH, J. Análise retórica. In: BAUER, M. W.; GASKELL, G. Pesquisa qualitativa com texto, imagem e som: um manual prático. 13. ed. Petrópolis: Vozes, 2002.

MEYER, M. A Retórica. São Paulo: Ática, 2007.

MELO JUNIOR, J. N. B. Aspectos textuais e conversacionais na entrevista oral no radiojornalismo alagoano. 2016. 176 f. Dissertação (Mestrado em Letras e Linguística) Programa de Pós-Graduação em Letras e Linguística, Universidade Federal de Alagoas, Maceió, 2016.

MORAIS, E. P. O macroethos racional e o afetivo na argumentação do julgamento do impeachment da ex-presidente Dilma Rousseff. Campinas: Pontes Editores, 2019.

PERELMAN, C.; OLBRECHTS-TYTECA, L. Tratado da argumentação: a nova retórica. 3. ed. São Paulo: Martins Fontes, [1958] 2014.

REBOUL, O. Introdução à Retórica. São Paulo: Martins Fontes, 2004.

ROCHA, M. S.; SANTOS, M. F. O. Análise retórica do gênero discursivo sermão oral. Polifonia, Cuiabá, v. 25, n. 37.1, p. 88-106, jan./abr. 2018.

ROCHA, M. S. As práticas argumentativas de oradores religiosos cristãos do agreste alagoano. 2020. 151 f. Dissertação (Mestrado em Linguística) - Programa de Pós Graduação em Linguística e Literatura, Universidade Federal de Alagoas, Maceió, 2020.

SILVA, L. N. O orador Jesus Cristo e suas técnicas argumentativas: um estudo retórico no Sermão do Monte. 2013. 128 f. Dissertação (Mestrado em Estudos de Linguagens) Universidade do Estado da Bahia, Salvador, 2013. 


\section{Sobre os autores}

Max Silva da Rocha (Orcid iD: http://orcid.org/0000-0002-6333-5532)

Doutorando no Programa de Pós-Graduação em Linguística e Literatura da Universidade Federal de Alagoas (UFAL); mestre em Linguística pela mesma instituição; especialista em Linguística Aplicada em Educação pela Universidade Candido Mendes (UCAM); licenciado em Letras Português pela Universidade Estadual de Alagoas (UNEAL). É professor do curso de Letras da Universidade Estadual de Alagoas (UNEAL).

\section{Deywid Wagner de Melo}

Doutor e mestre em Linguística pela Universidade Federal de Alagoas (UFAL); especialista em Gestão e Desenvolvimento Universitário pela mesma instituição; graduado em Letras Português/Inglês pela Universidade Estadual de Alagoas (UNEAL). É professor da Faculdade de Letras da UFAL.

Recebido em mês de 2020.

Aprovado em mês de 2020. 